horses, camels, elephants, ground sloths, and other animals which were accidentally trapped in the asphalt. Unfortunately, the detailed description of the collection is little more than begun.

Other papers discuss the discoveries of fossil man in association with extinct mammals in North America, and Dr. Merriam summarizes the results in an address which was delivered to the International Geological Congress at Washington in 1933. There seems to be no doubt that typically modern man lived in North America with some of the large mammals which became extinct before historic times.
The technical papers are followed by reprints of some popular articles on the same subjects; and the final volume is devoted chiefly to miscellaneous addresses and to papers on the educational use of the national parks. Dr. Merriam has done great service in providing guides and exhibits to help the public to appreciate the scientific interest of the vast open spaces which the United States Government has preserved for their enjoyment. His activities have indeed been numerous and varied, and the volumes before us form an imposing record of the life-work of a leading man of science.

A. S. W.

\title{
Popular Astronomy
}

\section{(I) Everyman's Astronomy}

By Mary Proctor. Pp. viii $+246+23$ plates. (London: The Scientific Book Club, 1939.) 2s. $6 d$.

(2) Starcraft

By William H. Barton, Jr., and Joseph Maron Joseph. Pp. vii +228 . (New York and London: McGraw-Hill Book Co., Inc., 1938.) 10s. 6d.

THE title of Miss Proctor's book is rather misleading, as it suggests a general elementary treatise. Actually, it is a collection of seventeen disconnected essays on astronomical subjects, written in a popular style. In its general scope it is somewhat reminiscent of the many similar volumes of essays published, sixty or seventy years ago, by the author's distinguished father, the late R. A. Proctor.

There is some internal evidence to suggest that the various chapters were written at different times. This has resulted in some repetitions and contradictions, and the attempt to bring the details up to date has not always been very successful. Perhaps the most interesting part of the book is to be found in the last seven essays, all of which deal with the subject of meteoric astronomy. Here the author has collected a considerable number of facts and numerical data relating to the more famous falls of meteorites, and these notes may be found useful for reference by other popular writers and lecturers.

The chief objection to the book is that it has throughout such a strong nineteenth-century flavour. The author appears only partly to have digested the results of modern research, and often quotes the necessarily tentative ideas of out-ofdate authorities on matters which have long since ceased to be subjects for mere speculation.

There is also a tendency to dwell at great length on trivial points, while more important matters are either passed over or put in a way that can only mislead or mystify the reader. A few misprints occur in the book, but they are mostly too obviously such to be of serious consequence. There are some fine illustrations, though one is wrongly described in its legend.

(2) Messrs. Barton and Joseph have written their book for American schoolchildren. It is, in a sense, a field-book of elementary practical astronomy. The principal constellations are taken separately. A diagram of each is given, with instructions for finding it at various seasons of the year; and some short notes on the chief objects contained in it are added. There are also photographs of some of these objects, obtained with the large American telescopes.

Simple instructions are given for the making of a sundial and other astronomical instruments, including a reflecting telescope. With regard to the latter, we are inclined to think that any young person capable of following successfully the very abbreviated directions supplied would scarcely be satisfied with so scrappy a treatment of the subject.

There are some inaccuracies of statement in the book ; for example, it is alleged that the companion of Polaris is visible in a field-glass, and that Saturn's rings are invisible to the naked eye because of their "faintness". The derivation of geocentric is given as "geus, the earth, and centric, the centre", while heliocentric is said to be derived from "helio, the sun, and centric, to circle about"!

The tone of the book is rather condescending, and the authors' attempts to be colloquial are often quite pathetic. Of course, American children may prefer "squinting" through a telescope to merely "looking" through it, like other people. All we can say is that those we have met have not seemed "that dumb".

W. H. Steavenson. 